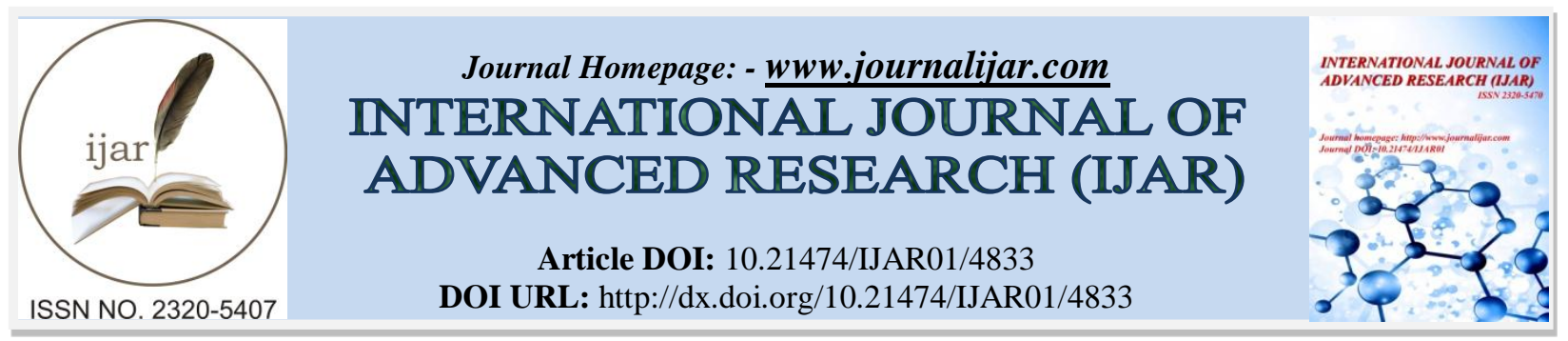

RESEARCH ARTICLE

\title{
A STUDY OF INCIDENCE OF CONGENITAL ANOMALIES IN A TERTIARY CARE CENTRE
}

Dr. Jothi sundaram md og, and Dr. d. s. kavitha md og.

1. Associate professor, Department of O\&G, Madurai Medical College, Madurai.

2. Assistant Professor, Department of O\&G, Madurai Medical College, Madurai.

\section{Manuscript Info}

Manuscript History

Received: 13 May 2017

Final Accepted: 15 June 2017

Published: July 2017

Key words:-

Congenital Anomalies ,

Ultrasonography, Incidence

\section{Abstract}

Congenital anomalies are also known as birth defects, congenital disorders or congenital malformations. Congenital anomalies can be defined as structural or functional anomalies that occur during intrauterine life and can be identified prenatally, at birth, or sometimes may only be detected later in infancy, such as hearing defects.Congenital anomalies are an important cause of neonatal mortality both in developed and developing countries. It accounts for $8-15 \%$ of perinatal deaths and $13-16 \%$ of neonatal deaths in India.It is not only a leading cause of fetal loss, but also contributes significantly to preterm birth, childhood and adult morbidity along with considerable repercussion on the mothers and their families.

Aim:- To study the incidence of congenital anomalies and the associated risk factors in Department of obstertrics and gynecology at GovtRajaji Hospital, attached to Madurai medical college , Madurai.

Method:- This study was conducted between OCTOBER 2016 to JANUARY 2017 , among 3088 mothers attending AN op were screened for congenital anomalies Relevant information regarding maternal age, gestational age, sex, birth order and consanguinity was documented. Significant antenatal history like maternal illness, ingestion of drugs, exposure to radiation was recorded. Antenatal ultrasonography (USG) findings were noted, there were 74 babies with congenital anomalies, overall incidence of congenital anomalies was 2.39

Copy Right, IJAR, 2017,. All rights reserved.

\section{Result:-}

A total of 3088 women who attended AN OP was screened and 74 babies were found to have congenital anomalies and those mothers were admitted and lethal anomalies were terminated. The incidence of congenital anomalies was $\mathbf{2 . 3 9 \%}$ ) In this analysis risk factors found to be significantly associated with CONGENITAL ANOMALY were age, increasing parity, most of the cases were diagnosed during second trimester anomaly scan, previous h/o congenital anomalies, and drug intake during first trimester.

\section{Interpretation and Conclusion:-}

This STUDY has highlighted incidence of congenital anomaly was found to be $\mathbf{2 . 3 9 \%}$ per cent at GRH Madurai, and the type of congenital anomalies in our locality. Regular antenatal visits and prenatal diagnosis are recommended for prevention, early intervention and even planned termination, when needed. 


\section{Study Report:-}

Incidence With Maternal Age.

\begin{tabular}{|c|c|c|}
\hline MATERNAL AGE & NO OF CASES & PERCENTAGE \\
\hline $18-20$ & 9 & $12.1 \%$ \\
\hline $21-30$ & 60 & $81.1 \%$ \\
\hline $31-40$ & 4 & $5.4 \%$ \\
\hline 41 & 1 & $1.35 \%$ \\
\hline
\end{tabular}

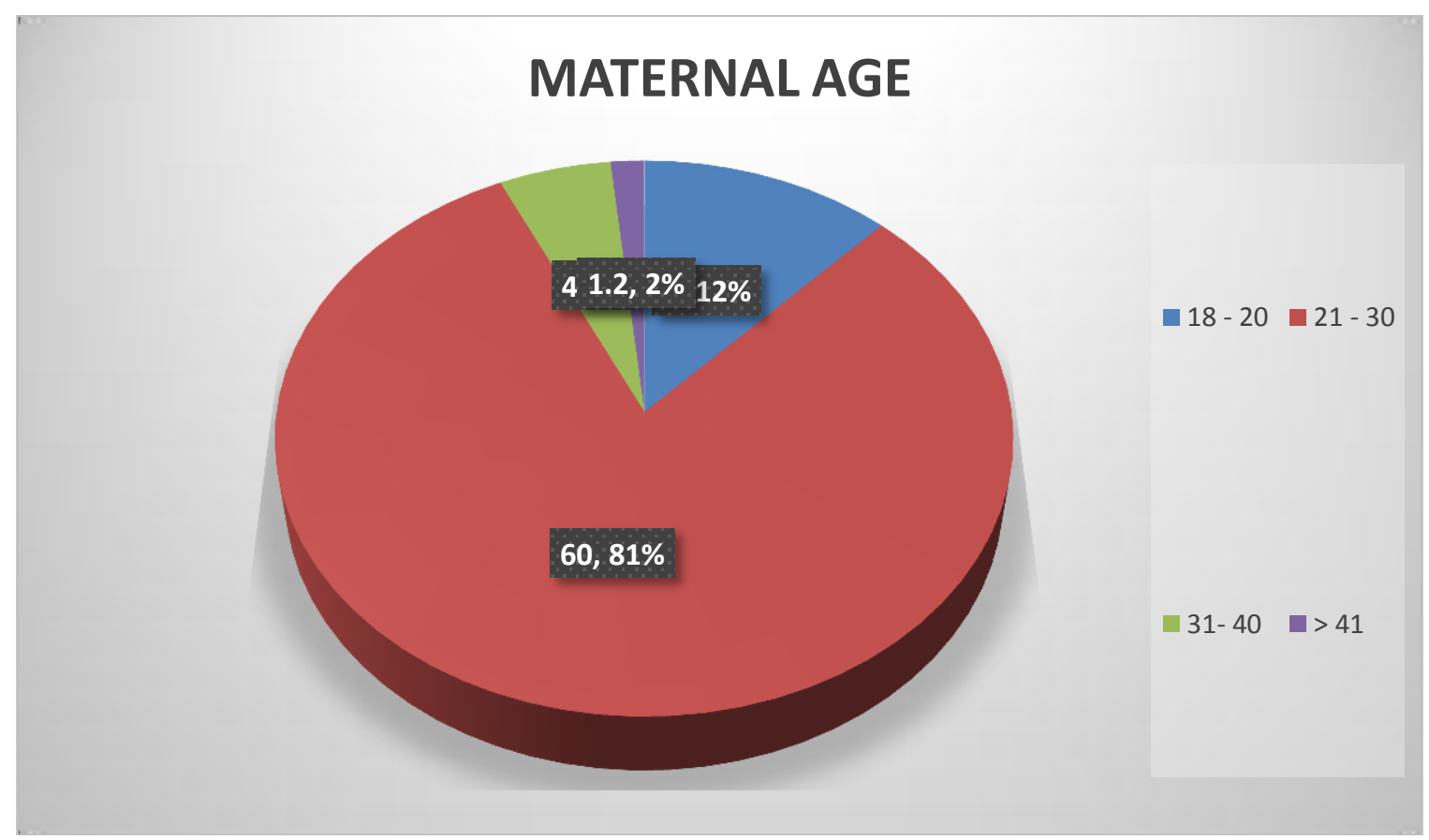

Incidence With Parity:-

\begin{tabular}{|c|c|c|}
\hline PARITY & NO OF CASES & PERCENTAGE \\
\hline PRIMI & 30 & $40.5 \%$ \\
\hline G2 & 33 & $14.5 \%$ \\
\hline G3 & 8 & $2.8 \%$ \\
\hline G4 & 2 & $1.35 \%$ \\
\hline G5 & 1 & \\
\hline
\end{tabular}


Incidence With Parity:-
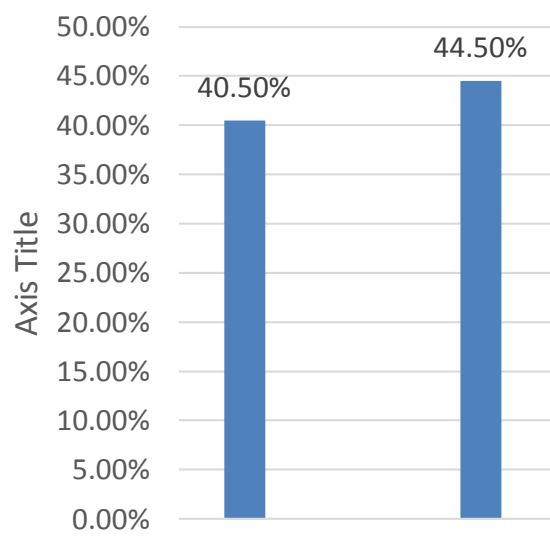

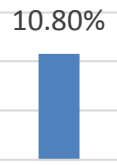

G3

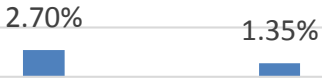

G4

G5

Axis Title

PERCENTAGE

Incidence With Maternal Age.

\begin{tabular}{|l|c|c|}
\hline GESTATIONAL AGE & NO OF CASES & PERCENTAGE \\
\hline $0-13 \mathrm{WKS}$ & 2 & $2.7 \%$ \\
\hline $14-28 \mathrm{WKS}$ & 45 & $60.8 \%$ \\
\hline $29-40 \mathrm{WKS}$ & 25 & $33.7 \%$ \\
\hline$>40 \mathrm{WKS}$ & 2 & $2.7 \%$ \\
\hline
\end{tabular}

Consagunity With Congenital Anomalies.

\begin{tabular}{|l|l|c|}
\hline DEGREE OF CONSAGUNITY & NO OF CASES & PERCENTAGE \\
\hline NON CONSAGUNOUS & 57 & $77 \%$ \\
\hline IST DEGREE & NIL & NIL \\
\hline $2^{\text {ND }}$ DEGREE & 7 & $9.4 \%$ \\
\hline $3^{\text {RD }}$ DEGREE & 15 & $20.2 \%$ \\
\hline
\end{tabular}

Types Of Anomaly.

\begin{tabular}{|c|c|}
\hline SYSTEM & NO OF CASES \\
\hline CENTRAL NERVOUS SYSTEM & 23 \\
\hline GENITOURINARY SYSTEM & 9 \\
\hline RESPIRATORY SYSTEM & 7 \\
\hline CARDIOVASULAR SYSEM & 6 \\
\hline GASTRO INTESTINAL SYSTEM & 8 \\
\hline MUSCULOSKELETAL SYSTEM & 7 \\
\hline OTHERS & 5 \\
\hline SYNDROME & DOWNS SYNDROME 1 \\
\hline
\end{tabular}

( Table includes all anomalies ,few anomalies with multisystem involvement are also included under each system ) Isolated Soft Markers.

\begin{tabular}{|l|c|}
\hline ECHOGENIC INTRACARDIAC FOCI & 10 \\
\hline MILD PYLECTASIS & 10 \\
\hline ECHOGENIC BOWEL & 1 \\
\hline MILD VENTRICULOMEGALY & 1 \\
\hline CHOROID PLEXUS CYST & 2 \\
\hline
\end{tabular}


Table Showing List Of Anomalies.

\begin{tabular}{|c|c|}
\hline \multicolumn{2}{|l|}{ Cns } \\
\hline Anencephaly & 4 \\
\hline Hydrocephalus & 10 \\
\hline Arnold Chiari Malformations & 2 \\
\hline Spina Bifida & 7 \\
\hline Menigoencephalocele & 1 \\
\hline Cerebellar Hypoplasia & 1 \\
\hline \multicolumn{2}{|l|}{ Musculoskeletal System } \\
\hline Ctev & 3 \\
\hline Arthrogyposis & 3 \\
\hline Hemimelia & 1 \\
\hline \multicolumn{2}{|l|}{ Respiratory System } \\
\hline Congenital Diaphagmatic Hernia & 3 \\
\hline Cpam Type 2 & 1 \\
\hline Bronchogenic Cyst & 1 \\
\hline Hypoplastic Lung Associated With Other Anomaly & 2 \\
\hline \multicolumn{2}{|l|}{ Cardiovasular System } \\
\hline Vsd & 2 \\
\hline Pda & 1 \\
\hline Double Outlet Right Venticle With Hypoplastic Left Ventricle & 1 \\
\hline Fetal Cardiomyopathy & 1 \\
\hline Hypoplastic Left Heart Syndrome & 1 \\
\hline \multicolumn{2}{|l|}{ Genitourinary System } \\
\hline Arpkd & 2 \\
\hline Dysplastic Kidney & 1 \\
\hline B/L Renal Cyst & 1 \\
\hline Puj Obstruction & 2 \\
\hline B/L Hydronephrosis & 1 \\
\hline Hydronephrosis & 1 \\
\hline Puj Obstruction With Blader Outlet Obstruction & 1 \\
\hline \multicolumn{2}{|l|}{ Git } \\
\hline Cleft Lip & 1 \\
\hline Cleft Lip \& Cleft Palate & 5 \\
\hline Fetal Spleenomegaly & 1 \\
\hline Fetal Ascites & 1 \\
\hline \multicolumn{2}{|l|}{ Others } \\
\hline Fetal Hydrops & 3 \\
\hline B/L Meatal Atresia & 1 \\
\hline Ovarian Cyst With Internal Hemorrhage & 1 \\
\hline
\end{tabular}

Consolidation Of Anomalies:-

\begin{tabular}{|l|l|}
\hline LETHAL ANOMALIES & 28 \\
\hline NON LETHAL ANOMALIES & 26 \\
\hline ISOLATED SOFT MARKERS & 20 \\
\hline
\end{tabular}

\section{Results:-}

During the study period, 3088 MOTHER were screened in AN OP, those mothers who were carrying anomalous babies were admitted and evaluated, of which 74 babies were found to have congenital malformations, making the incidence of $\mathbf{2 . 3 9 \%}$.

The predominant system involved was central nervous system (31.1\%) followed by renal system (12.1\%) and gastrointestinal system (10.8\%). Talipes (4.05\%) was the most common anomaly seen in the musculoskeletal group and likewise cleft lip (1.35\%) and cleft palate (6.75\%) in GI system and hydrocephalus(13.5\%) in CNS. 
Regarding the parity of the mothers, 30 were primiparas and rest 33 were multiparas. Cases of congenital anomaly were found in $40 \%$ of primipara, whereas in multipara, the proportion was $44.5 \%$. This was not statiscally significant.But this was similar with other studies.It has been seen that more than half of the mothers were aged between 20 and 30 years $(81.1 \%)$ with only $7 \%$ of the mothers were over the age of 30 years. The incidence of congenitally anomalous babies born was $12 \%$ for mothers $<20$ years, and $1.2 \%$ for $>40$ years. However, this difference was statistically significant.

In this study 22 mothers had a history of consanguinity and all of them showed some congenital anomaly (29.6\%) in their babies, whereas in non-consanguineous couples, the incidence was more. This was found to be stastically significant. Most of the anomalies were detected in second trimester $(60.8 \%)$.

Exposure to drugs was noted in ONE mothers who was on antipsychotic drugs, and was diagnosed to have congenital malformed baby.

Previous history of congenital anomaly was in one woman who previously had one child with ARPKD was diagnosed and was terminated, her second child was also diagnosed with ARPKD and was terminated.

None of mothers who delivered congenitally malformed babies gave history of exposure to radiation, smoking or alcohol during the pregnancy

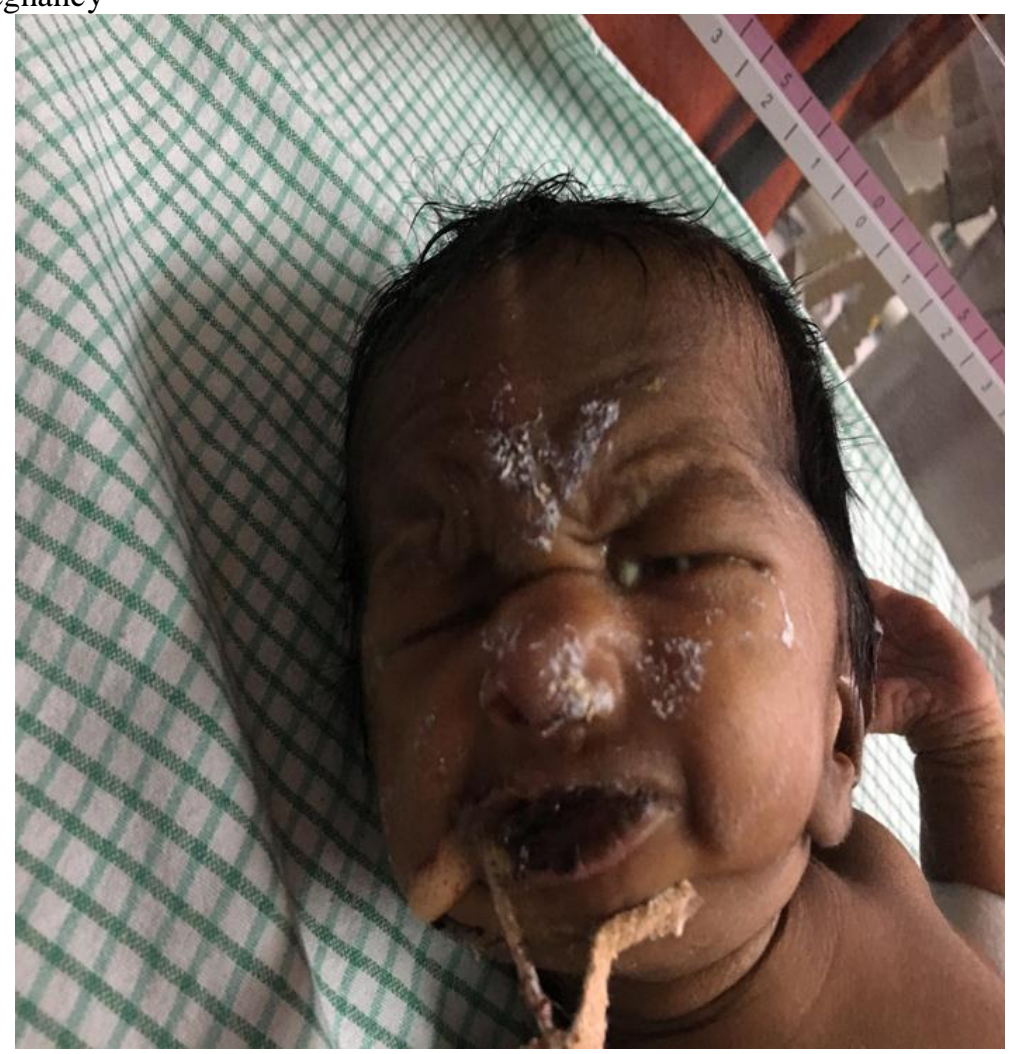




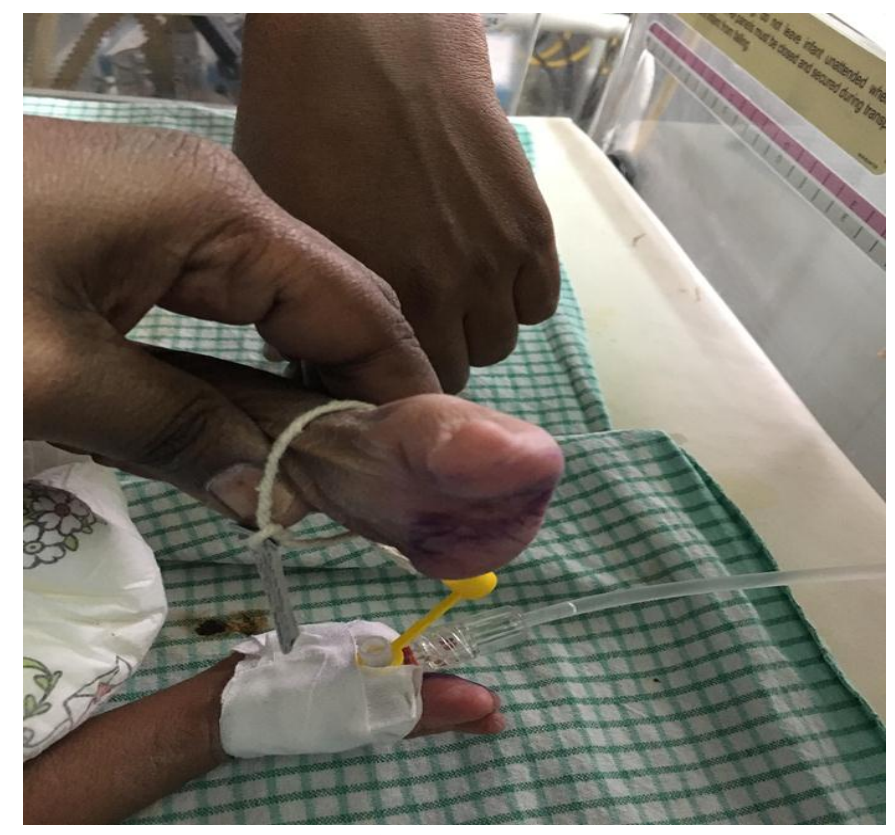

Multiple Congenital Anomalies ( Microophtalmia, Fish Mouth, Hemimelia)

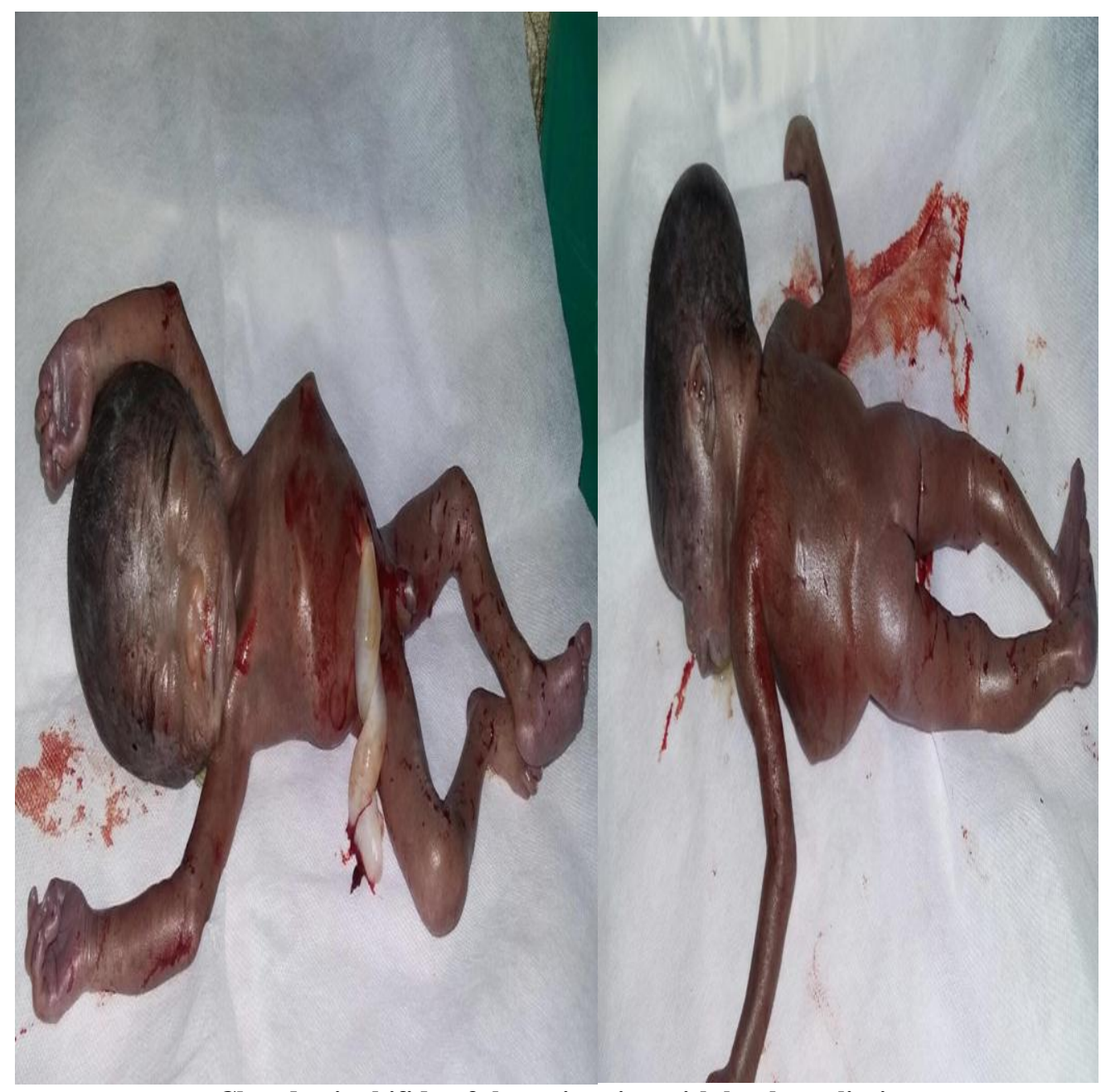

Closed spinabifida of thoracic spine with kyphoscoliosis 


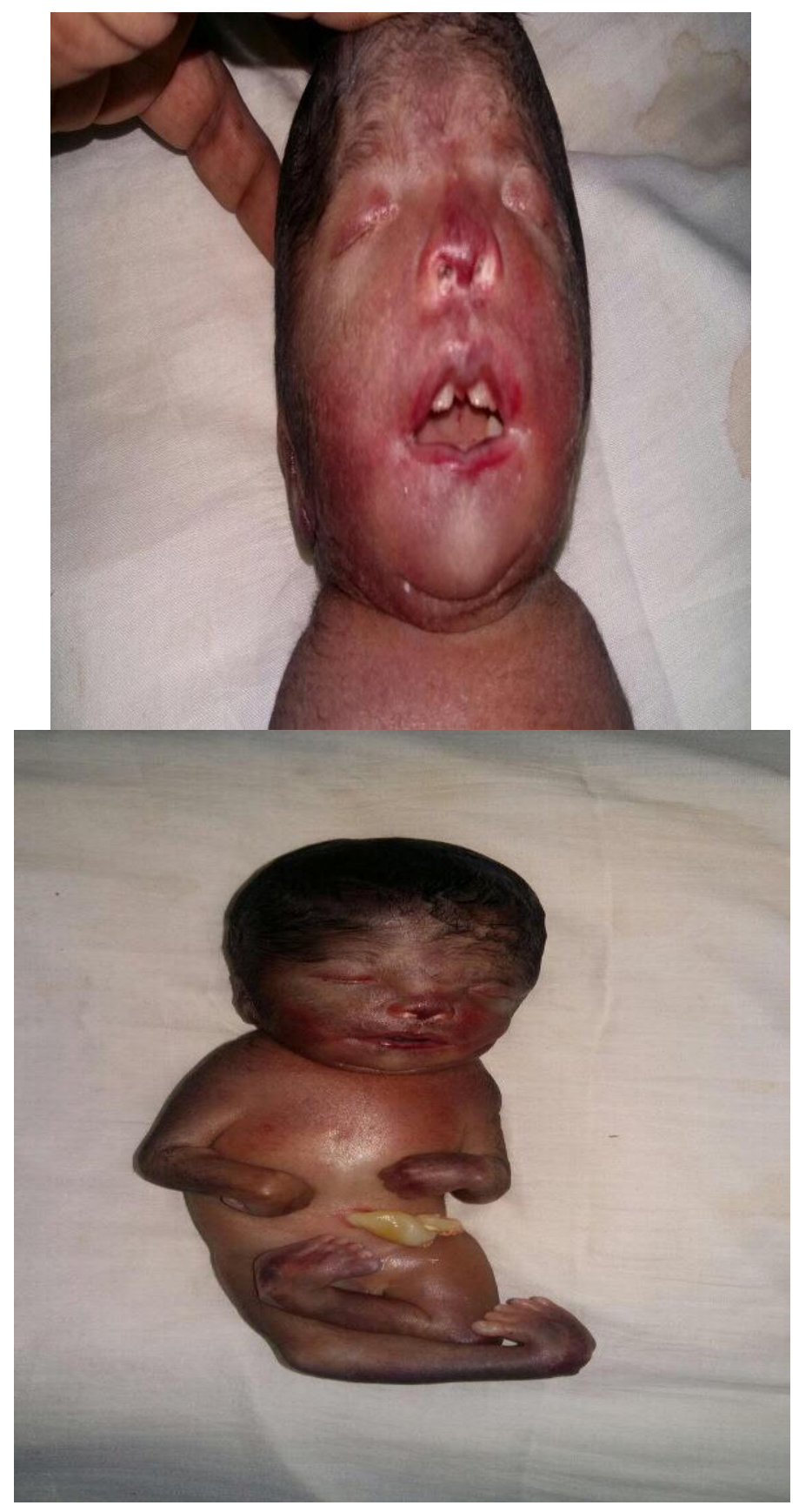




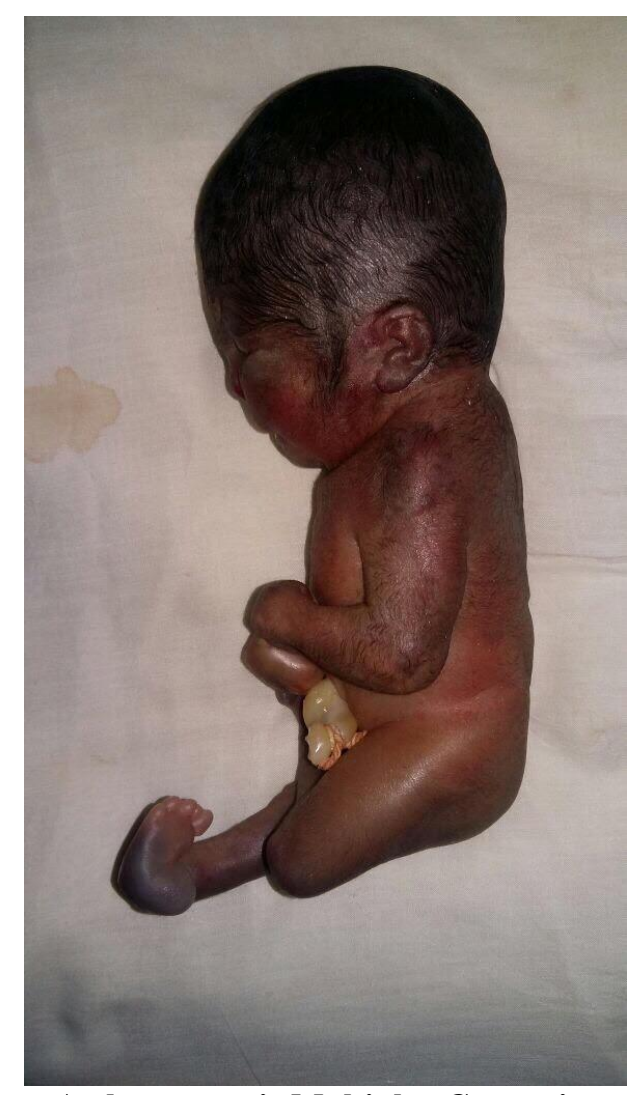

Arthrogryposis Multiplex Congenita

Lumbar Myelomeningocele

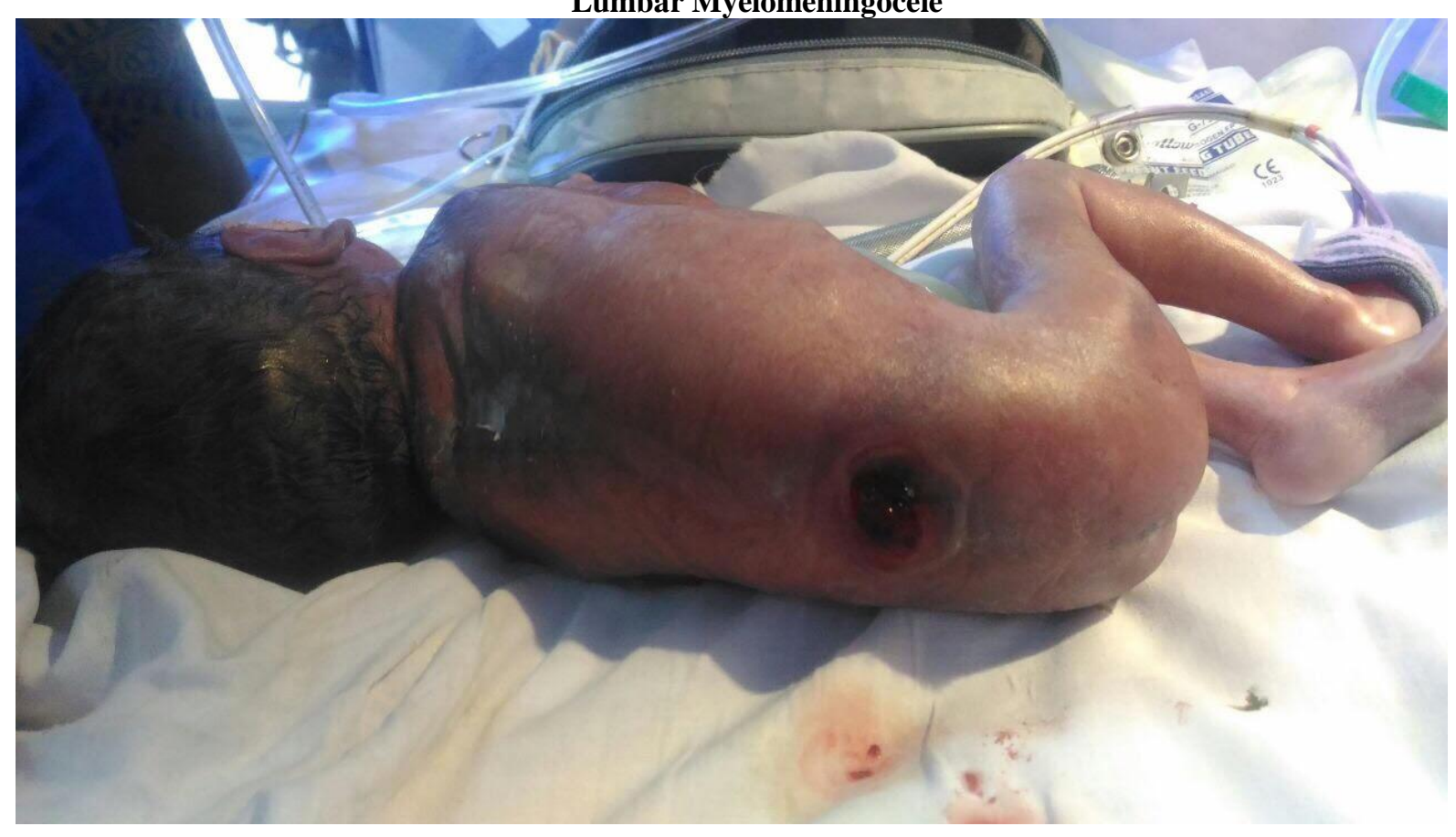




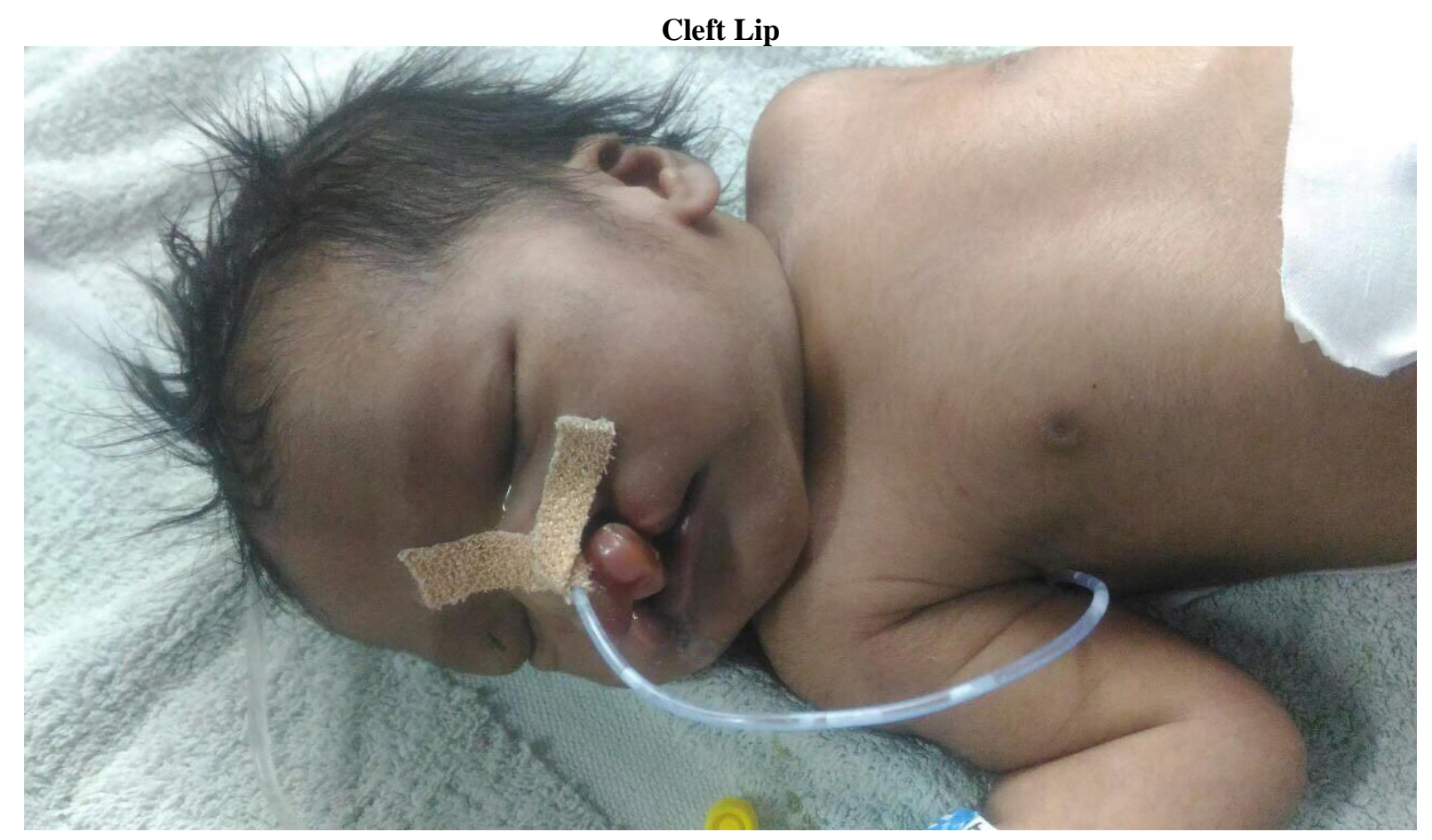

\section{Discussion:-}

In the present study, the INCIDENCE of congenital malformations in the newborns were $2.39 \%$, which is comparable with the earlier studies from India, which reported incidence of $2.72 \%$ and $1.9 \%$.[1,2,4,5] Although we got nearly the same result as reported in other studies, $[1,2,4,5,7,8,9]$.

With regard to pattern of congenital anomalies in the study, the most common system involved was central nervous system (33.2\%), followed by genitourinary (15\%), GIT (11.2\%), MUSCULOSKELETAL (10.5\%), cardiovascular system $(9.1 \%)$, etc.,.Some studies however recorded higher incidence of CNS malformations[2,6,7,8,9] followed by GIT and musculoskeletal system, [9] .

Previous studies have reported significantly higher incidence of malformations among the multiparas. Our result is consistent with this finding, which indicates a positive correlation between the birth order and the incidence of congenital anomalies.[5].

\section{Refrence:-}

1. Taksande A, Vilhekar K, Chaturvedi P, Jain M. Congenital malformations at birth in Central India: A rural medical college hospital based data. Indian J Hum Genet. 2010;16:159-63. [PMC free article]

2. Tomatir AG, Demirhan H, Sorkun HC, Köksal A, Ozerdem F, Cilengir N. Major congenital anomalies: A fiveyear retrospective regional study in Turkey. Genet Mol Res. 2009;8:19-27.

3. Gupta RK, Singh A, Gupta R. Pattern of congenital anomalies in newborn at birth: A hospital based prospective study. Proceedings of the 42nd National Conference of Indian Academy of Pediatrics (Pedicon); Jan 6-9; Kolkata, India. 2005.

4. . Dutta V, Chaturvedi P. Congenital malformations in rural Maharashtra. Indian Pediatr. 2000;37:998-1001.

5. Hudgins L, Cassidy SB. Congenital anomalies. In: Martin RJ, Fanaroff AA, Walsh MC, editors. NeonatalPerinatal Medicine. 8th ed. Philadelphia: Mosby-Elsevier; 2006

6. Madi SA, Al-Naggar RL, Al-Awadi SA, Bastaki LA. Profile of major congenital malformations in neonates in Al-Jahra region of Kuwait. East Mediterr Health J. 2005;11:700-6.

7. Congenital malformations in Shimla.Indian J Pediatr. 2000 Apr;67(4):249-51

8. Congenital malformations at birth.Indian Pediatr. 1994 Oct;31(10):1187-91

9. Congenital malformations in the newborn--a prospective studyIndian Pediatr. 1989 Jan;26(1):32-5. 